\title{
Determination of nine high-intensity sweeteners in various foods by high-performance liquid chromatography with mass spectrometric detection
}

\author{
Agata Zygler • Andrzej Wasik • Agata Kot-Wasik • \\ Jacek Namieśnik
}

Received: 14 February 2011 /Revised: 9 March 2011 / Accepted: 20 March 2011 /Published online: 5 April 2011

(C) The Author(s) 2011. This article is published with open access at Springerlink.com

\begin{abstract}
An analytical procedure involving solid-phase extraction (SPE) and high-performance liquid chromatography-mass spectrometry has been developed for the determination of nine high-intensity sweeteners authorised in the EU; acesulfame-K (ACS-K), aspartame (ASP), alitame (ALI), cyclamate (CYC), dulcin (DUL), neohesperidin dihydrochalcone (NHDC), neotame (NEO), saccharin (SAC) and sucralose (SCL) in a variety of food samples (i.e. beverages, dairy and fish products). After extraction with a buffer composed of formic acid and $N, N$ diisopropylethylamine at $\mathrm{pH} 4.5$ in ultrasonic bath, extracts were cleaned up using Strata-X $33 \mu \mathrm{m}$ Polymeric SPE column. The analytes were separated in gradient elution mode on $\mathrm{C}_{18}$ column and detected by mass spectrometer working with an electrospray source in negative ion mode. To confirm that analytical method is suitable for its intended use, several validation parameters, such as linearity, limits of detection and quantification, trueness and repeatibilty were evaluated. Calibration curves were linear within a studied range of concentrations $\left(r^{2} \geq 0.999\right)$ for six investigated sweeteners (CYC, ASP, ALI, DUL, NHDC, NEO). Three compounds (ACS-K, SAC, SCL) gave non-linear response in the investigated concentration range. The method detection limits (corresponding to signal-to-noise $(\mathrm{S} / \mathrm{N})$ ratio of 3$)$ were below $0.25 \mu \mathrm{g} \mathrm{mL}$ $\left(\mu \mathrm{g}^{-1}\right)$, whereas the method quantitation limits (corresponding to $\mathrm{S} / \mathrm{N}$ ratio of 10 ) were below $2.5 \mu \mathrm{g} \mathrm{mL}^{-1}\left(\mu \mathrm{g} \mathrm{g}^{-1}\right)$. The recoveries at the tested concentrations $(50 \%, 100 \%$ and $125 \%$ of maximum usable
\end{abstract}

\footnotetext{
A. Zygler · A. Wasik $(\triangle) \cdot$ A. Kot-Wasik $\cdot$ J. Namieśnik Department of Analytical Chemistry, Chemical Faculty, Gdańsk University of Technology,

ul. G. Narutowicza 11/12,

80-233 Gdańsk, Poland

e-mail:wasia@pg.gda.pl
}

dose) for all sweeteners were in the range of $84.2 \div 106.7 \%$, with relative standard deviations $<10 \%$ regardless of the type of sample matrix (i.e. beverage, yoghurt, fish product) and the spiking level. The proposed method has been successfully applied to the determination of the nine sweeteners in drinks, yoghurts and fish products. The procedure described here is simple, accurate and precise and is suitable for routine quality control analysis of foodstuffs.

Keywords High-intensity sweeteners · Solid-phase extraction · Liquid chromatography · Mass spectrometry . Food analysis

\section{Introduction}

Sweet taste is favoured by human beings. People instinctively desire the pleasure of sweetness, which resulted in preference for sweet foods and beverages. Due to negative health effects of consuming the most popular agent for food flavouring - sugar (often called "sweet poison") — an intensive research for valuable sugar alternatives has taken place. Nowadays, there is a wide assortment of sugar substitutes available on the market. High-intensity (often known as intense, low-calorie, high-potency or nonnutritive) sweeteners form an important group of sugar alternatives. These substitutes are much sweeter than sugar (from 30 to 13,000 times). Because of their high sweetening strength, the amounts needed to achieve desired sweetness of food products are so small that they are considered virtually non-caloric [1].

Epidemic obesity and diabetes encouraged the growth of consumption of products containing high-intensity sweeteners. A broad variety of low- or reduced-calorie food and 
beverages are available to consumers who want to enjoy sweet taste and, at the same time, want to maintain a balanced diet without any extra calories [2]. Sweeteners can be found in almost all products including soft drinks and table-top sweeteners (the biggest applications of low-calorie sweeteners), dairy products such as yoghurt and ice cream, desserts, chewing gums and sweets, condiments such as salad dressings, mustards and sauces and many other products.

Due to concern on the consumer safety, a legislation which limits the content of food additives in foodstuffs has been introduced. The European Union directive 94/35/EC (also known as the "Sweeteners Directive") [3] with four amendments 96/83/EC [4], 2003/115/EC [5], 2006/52/EC [6] and 2009/163/EU [7] is important tool that restricts the level at which certain sweeteners may be present in a specific type of food. These amendments were accepted in order to keep pace with technological developments in the field of sweeteners and indicate the maximum level of use of each high-potency sweetener in a specific food category. The maximum level at which sweeteners may be added to foodstuffs is called maximum usable dose (MUD). Since the numerous food products contain a combination of sweeteners, their control with respect to agreement with legislation is essential.

There are lots of methods developed for determination of high-intensity sweeteners in various foodstuffs [8]. These methods are based on different analytical techniques including high-performance liquid chromatography (HPLC), ion chromatography, thin-layer chromatography, gas chromatography, capillary electrophoresis, flow injection analysis, electroanalytical techniques and spectroscopic techniques [9-20]. However, most of them are suitable only for determination of one sweetener or simple sweetener mixtures (two to four compounds).

The most common methods employed for simultaneous determination of several sweeteners are chromatographic methods, in particular, high-performance liquid chromatography. The main problem in the area of simultaneous determination of complex sweetener mixtures is that the analytes posses significantly different physicochemical, electrochemical and spectral properties. As a result, there is a very limited choice of detection systems capable of detecting compounds from diverse chemical groups in one single analysis. The most commonly used detector in conjunction with HPLC is a spectrophotometric detector that enables detection of most non-nutritive sweeteners, i.e. acesulfame-K (ACS-K), aspartame (ASP), alitame (ALI), dulcin (DUL), neotame (NEO), neohesperidin dihydrochalcone (NHDC) and saccharin (SAC). Since cyclamate (CYC) and sucralose (SCL) do not absorb in the UV/ visible range due to a lack of chromophore group, UV detection is not suitable in this case [8]. Some complicated and time-consuming procedures are necessary for the absorbance detection of these sweeteners in HPLC (e.g. derivatization). The application of mass spectrometric detector (MSD) and evaporative light scattering detector (ELSD) seems to be suitable tools for detection of compounds possessing different chemical properties. Only few procedures have been proposed that are able to determine a wide range of non-nutritive sweeteners in a single analysis. Nine intense sweeteners (ACS-K, ASP, ALI, CYC, SAC, NEO, NHDC, SCL and DUL) were successfully separated and quantitated in various food products by means of HPLC-ELSD [21]. However, in many cases, simultaneous quantitation and confirmation is desired, especially when there is a need to deal with samples characterised by complex matrices such as food samples. For that reason, procedures based on highperformance liquid chromatography-mass spectrometry (HPLC/MS) seem to be superior over the previously described procedure involving ELSD. In recent years, the role of HPLC/MS technique has gained widespread recognition in the field of food quality control. The first proposed HPLC/MS procedure allows six artificial (ACS$\mathrm{K}, \mathrm{ASP}, \mathrm{CYC}, \mathrm{DUL}, \mathrm{SAC}, \mathrm{SCL}$ ) and three natural (stevioside, glycyrrhizin acid and rebaudioside A) high-intensity sweeteners to be determined [22]. The detection of analytes was performed in the electrospray ionisation (ESI) negative ion mode. However, this method has serious disadvantages associated with a lack of internal standards that can affect the quantitation of sweeteners. The other HPLC/MS method capable of determining eight sweeteners including acesulfame-K, alitame, aspartame, cyclamate, neotame, saccharin, sucralose and stevioside allows for more precise quantitation of analytes - warfarin sodium has been applied as internal standard [23].

In this study, we have explored potential usefulness of solid-phase extraction (SPE)-HPLC/MS procedure for accurate qualitative and quantitative analysis of a group of high-intensity sweeteners (ACS-K, ALI, ASP, CYC, DUL, NEO, NHDC, SAC and SCL) in various foodstuffs. A recently proposed HPLC/MS method for simultaneous determination of sweeteners in food products does not include any clean-up step [23]. A sample preparation was only based on extraction with methanol-water mixture and subsequent filtration of the extract. The methodology reported here consists of an extraction of analytes with a buffer composed of formic acid and $N, N$-diisopropylethylamine ( $\mathrm{pH} 4.5$ ) followed by extract clean-up using solidphase extraction and final separation and determination of analytes by HPLC/MS. New internal standard (methyl derivative of cyclamic acid) for mass spectrometric determination of high-intensity sweeteners is also proposed. The developed method has been successfully applied for analysis of over 30 different food samples such as drinks, 
juices, yoghurts and various fish products. To the best of our knowledge, no reports on the analysis of non-nutritive sweeteners in fish preserves, marinates, salads or pastes have been published up to date. Several validation parameters, such as linearity, limits of detection and quantification, repeatability and trueness were also evaluated. In general, the proposed methodology can be routinely applied by food control laboratories in order to simultaneously monitor the content of multiple highintensity sweeteners in a wide range of food products.

\section{Materials and methods}

\section{Reagents and materials}

The individual standards of studied artificial sweeteners were obtained from different sources: ACS-K from Nutrinova (Frankfurt am Main, Germany), ALI from Frapp's Pharma (Hong Kong, China), ASP from Ajinomoto (Switzerland), CYC from Merck (Germany), NEO from CHEMOS (Regenstauf, Germany), NHDC from SigmaAldrich (Germany), SCL from Nestlé (Obre, Switzerland), and SAC from Sigma-Aldrich (Germany); DUL was prepared according to [24]. Sodium $N$-phenylsulfamate, sodium $N$-amylsulfamate, sodium $N$-hexylsulfamate and sodium $\mathrm{N}$-(2-methylcyclohexyl)sulfamate tested as internal standard (IS) were prepared according to [25].

HPLC gradient-grade methanol was purchased from Merck (Darmstadt, Germany). Acetone (pure p.a.), formic acid (pure p.a.), ammonia (pure p.a.) were obtained from P. O.Ch. (Gliwice, Poland). N,N-diisopropylethylamine (DIPEA) was purchased from Sigma-Aldrich. Ultrapure water was obtained form an HLP5 system (Hydrolab, Poland).

Formate buffer solution (mobile phase component, $\mathrm{pH} 4.5$ ) was prepared by dissolving of $1.5 \mathrm{~mL}\left(20 \mathrm{mmol} \mathrm{L}^{-1}\right)$ of formic acid in $2 \mathrm{~L}$ of water and adjusting the $\mathrm{pH}$ to 4.5 with aqueous ammonia solution. The buffer solution was filtered through a $0.45 \mu \mathrm{m}$ regenerated cellulose membrane filter. Formic acid- $N, N$-diisopropylethylamine (FA-DIPEA) buffer solution ( $\mathrm{pH} 4.5$ ) used during sample preparation procedure was prepared in the same way, by titration of $1 \mathrm{~L}$ of $20 \mathrm{mmol} \mathrm{L}^{-1}$ solution of formic acid with DIPEA until desired $\mathrm{pH}$ was reached.

Food samples, i.e. sugar-free drinks, juices, yoghurts and fish products were purchased from the local supermarkets.

Preparation of standards and calibration solutions

Stock solutions of individual sweeteners were prepared by dissolution of pure sweeteners in water (ACS-K, SAC, CYC, SCL and ALI) or in methanol-water (1:1) mixture.
The concentrations of the individual solutions of ACS-K, SAC, CYC and SCL were ca. $50.0 \mathrm{mg} \mathrm{mL}^{-1}$, while in case of ASP, ALI, DUL, NEO, NHDC, ca. $10.0 \mathrm{mg} \mathrm{mL}^{-1}$. Stock solution of internal standard $\left(1.0 \mathrm{mg} \mathrm{mL}^{-1}\right)$ was prepared in water. Intermediate solutions of the mixture of five sweeteners (ACS-K, SAC, CYC, ASP and SCL, $1.0 \mathrm{mg} \mathrm{mL}^{-1}$ ) and four sweeteners (DUL, ALI, NEO, NHDC, $0.1 \mathrm{mg} \mathrm{mL} \mathrm{m}^{-1}$ ) were prepared in formic acid-ammonia buffer at $\mathrm{pH} 4.5$.

A series of calibration solutions were prepared by dilution of the intermediate solutions with the DIPEA buffer resulting in a concentration range of $0.1-$ $40.0 \mu \mathrm{g} \mathrm{mL}^{-1}$ for ACS-K, ASP, CYC, SAC, SCL and of $0.1-8.0 \mu \mathrm{g} \cdot \mathrm{mL}^{-1}$ for ALI, DUL, NHDC and NEO. In the calibration solutions, the concentration of internal standard was $10 \mu \mathrm{g} \mathrm{mL}^{-1}$. All solutions were stored in the dark, at $4^{\circ} \mathrm{C}$ and brought to room temperature before use.

Preparation of fortified test materials

All carbonated beverages were degassed by sonication for $15 \mathrm{~min}$, whereas yoghurts and fish products were homogenised using a food blender and, if necessary, a homogeniser (Ultraturax type).

In order to evaluate trueness of the method, $200 \mathrm{~g}$ of homogenised blank samples of the yoghurt, the home-made fish product and $200 \mathrm{~mL}$ of degassed cola drink (sugarsweetened) were spiked by adding the appropriate volumes of standard solutions of an individual sweetener. Three concentration levels for each test material were prepared, corresponding to $50 \%, 100 \%$ and $125 \%$ of a MUD value.

\section{Instrumentation}

The chromatographic analyses were performed using an Agilent 1100 series HPLC system. The chromatographic system consisted of G1313A autosampler, with the injection volume set to $10 \mu \mathrm{l}, \mathrm{G} 1312 \mathrm{~A}$ binary pump and G1316A thermostated column compartment connected in series with G1313A DAD detector and G1315B MSD mass spectrometer equipped with an electrospray probe. The separation of analytes was performed using Nucleodur C18 Pyramid $(250 \times 3 \mathrm{~mm}$, $5 \mu \mathrm{m})$ HPLC column (Macherey-Nagel, Germany). The 24-port vacuum manifold (Grace, USA) was used for solid-phase extractions. The food samples were extracted using SPE cartridges Strata-X $33 \mu \mathrm{m}$ Polymeric RP $3 \mathrm{~mL} / 200 \mathrm{mg}$ (Phenomenex, Germany). Degassing was carried out using an ultrasonic bath (Bandelin Sonorex), and homogenisation was carried out using a food blender (model BL740, Kenwood) and a homogeniser (model H 500, Pol-Eko Aparatura, Poland). 
Method

\section{Sample preparation}

In the case of beverages and juices, $5 \mathrm{~mL}$ of degassed drink or juice was added into a $50 \mathrm{~mL}$ volumetric flask and made up to the mark with FA-DIPEA buffer (pH 4.5).

Whereas considering yoghurts and fish products, $5 \mathrm{~g}$ of homogenised test material was weighted into a $50-\mathrm{mL}$ volumetric flask and made up to the mark with FA-DIPEA buffer. Subsequently, it was shaken vigorously and sonicated in ultrasonic bath for $10 \mathrm{~min}$. The content of the flask was transferred to $30 \mathrm{~mL}$ Falcon tube and centrifuged at 4,400 rpm for $10 \mathrm{~min}$.

Isolation of sweeteners from all prepared test materials was performed by solid-phase extraction. Strata-X RP cartridges were conditioned by passing $3 \mathrm{~mL}$ of methanol followed by three 2-mL portions of FA-DIPEA buffer (pH 4.5). In the next step, $2 \mathrm{~mL}$ of the supernatant from the Falcon tube was passed through the cartridge at flow rate of approximately $0.5-1 \mathrm{~mL} \mathrm{~min}^{-1}$. After the sample effused completely, the cartridge was washed with $3 \mathrm{~mL}$ portion of FA-DIPEA buffer. Finally, the analytes were eluted using two portions of $2 \mathrm{~mL}$ of methanol (equilibrating the sorbent bed with the first portion of methanol for $10 \mathrm{~min}$ ). Before HPLC/MS analysis, the IS was added to the final extract and the solution was made up to a volume of $10 \mathrm{~mL}$ with ammonium formate buffer (mobile phase component). The concentration of IS in the extract was $10 \mu \mathrm{g} \mathrm{mL}^{-1}$.

\section{HPLC/MS analyses}

The HPLC mobile phase components were prepared by mixing methanol with buffer solution and acetone (component A, 69+24+7; component B, $11+82+7 v / v / v)$. The composition of mobile phase was chosen according to previously described procedure [21], but triethylamine has been replaced with ammonia [26]. The mobile phase was degassed by sonication before analysis. The chromatographic separation of nine sweeteners and internal standard was performed using the following programmed gradient profile of 0-4 min, isocratic at $100 \% \mathrm{~B}, 4-14 \mathrm{~min}$; linear gradient from $100 \% \mathrm{~B}$ to $53 \% \mathrm{~B} ; 14-20 \mathrm{~min}$, linear gradient from $53 \% \mathrm{~B}$ to $0 \% \mathrm{~B} ; 20-24 \mathrm{~min}$, isocratic at $0 \% \mathrm{~B}, 24$ 26 min, back to $100 \% \mathrm{~B}, 26-36 \mathrm{~min} 100 \% \mathrm{~B}$ (column equilibrating). The total run time was $36 \mathrm{~min}$. The mobile phase flow rate used was $0.5 \mathrm{~mL} \mathrm{~min}^{-1}$, and the injection volume was $10 \mu \mathrm{l}$. The temperature of the column compartment was set to $22{ }^{\circ} \mathrm{C}$.

Electrospray ionisation in negative ion mode was employed. The operating parameters of the ESI source were as follows: capillary voltage $4,000 \mathrm{~V}$, nebulizer gas pressure $350 \mathrm{kPa}$, drying gas temperature $300^{\circ} \mathrm{C}$ and drying gas flow rate $12 \mathrm{Lmin}^{-1}$. Quantification of all compounds was performed using a time-scheduled selected ion monitoring mode. Ions corresponding to ACS-K, SAC and CYC $(m / z=162,182$ and 178 , respectively) were recorded between 0 and $10 \mathrm{~min}$ of analytical run. Within next timewindow (10-14.1 min), ions corresponding to IS and ASP were monitored $(m / z=192$ and 293 , respectively). SCL was monitored between 14.1 and $16 \mathrm{~min}$ using ion of $m / z=395$. DUL $(m / z=225)$ between 16 and $17.3 \mathrm{~min}$. ALI $(\mathrm{m} / \mathrm{z}=330)$ between 17.3 and $21 \mathrm{~min}$. NHDC $(\mathrm{m} / z=611)$ between 21 and $23 \mathrm{~min}$. NEO $(\mathrm{m} / \mathrm{z}=377)$ starting from the $23 \mathrm{rd}$ minute up to the end of analytical run.

\section{Results and discussion}

Mass spectrometric detection

All of the compounds under study ionise in negative electrospray mode. The most important variable affecting detector's response was fragmentor voltage. For most of the analytes, optimum fragmentor voltage was around $100 \mathrm{~V}$. In case of dulcin, optimum fragmentor voltage was remarkably low $(22 \mathrm{~V})$, whereas for neohesperidin dihydrochalcone, it was extremely high $(210 \mathrm{~V})$. The most intense signal in the spectra of almost all sweeteners comes from a quasimolecular ion $[\mathrm{M}-\mathrm{H}]^{-}$. The only exception is dulcin. In this case, the most intense signal comes from a formic aciddulcin adduct $\left[\mathrm{DUL}+\mathrm{HCOO}^{-}\right]^{-}$. Mass spectra of the compounds under the study, obtained in flow injection analysis (i.e., bypassing a chromatographic column) mode are shown in Fig. 1a-c.

\section{Selection of an internal standard}

Mass spectrometric detector used within this study was found unstable in terms of the sensitivity. Usually, the response for a given compound at the end of the day was just a half of the response at the beginning of the day. Therefore, it was crucial to find an internal standard that would compensate for such change in detector's response. Without an internal standard, quantitative analysis would be impossible.

A literature search revealed just two compounds that were used as internal standards during mass spectrometric determination of multiple artificial sweeteners; deuterated sucralose and sodium warfarin. The idea to use deuterated sucralose was abandoned due to its high cost and very limited availability. Sodium warfarin is, on the other hand, readily available, but since it is a drug, there is a remote, but still non-zero, probability that it can be present in the samples being analysed. Moreover, its long retention time makes it more suitable for compounds exhibiting similar, 
Fig. 1 Mass spectra and structures of the compounds under the study a
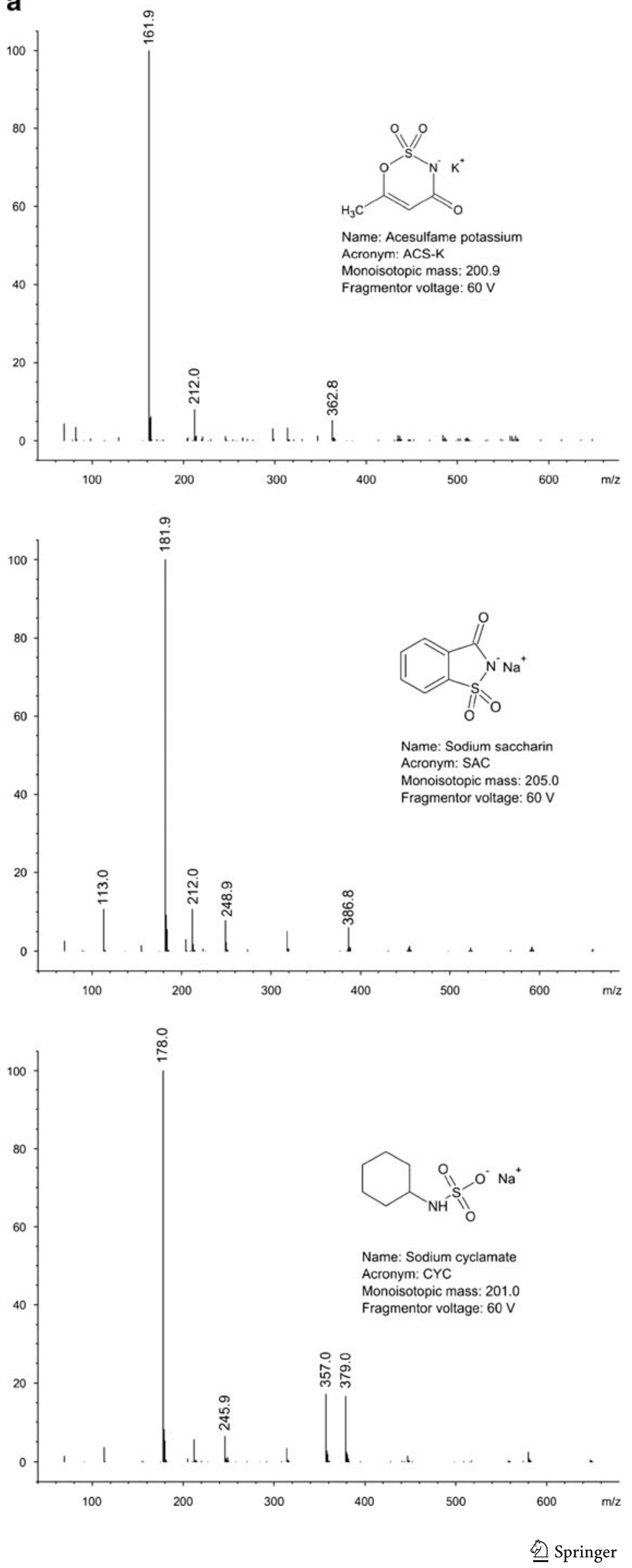
Fig. 1 (continued)
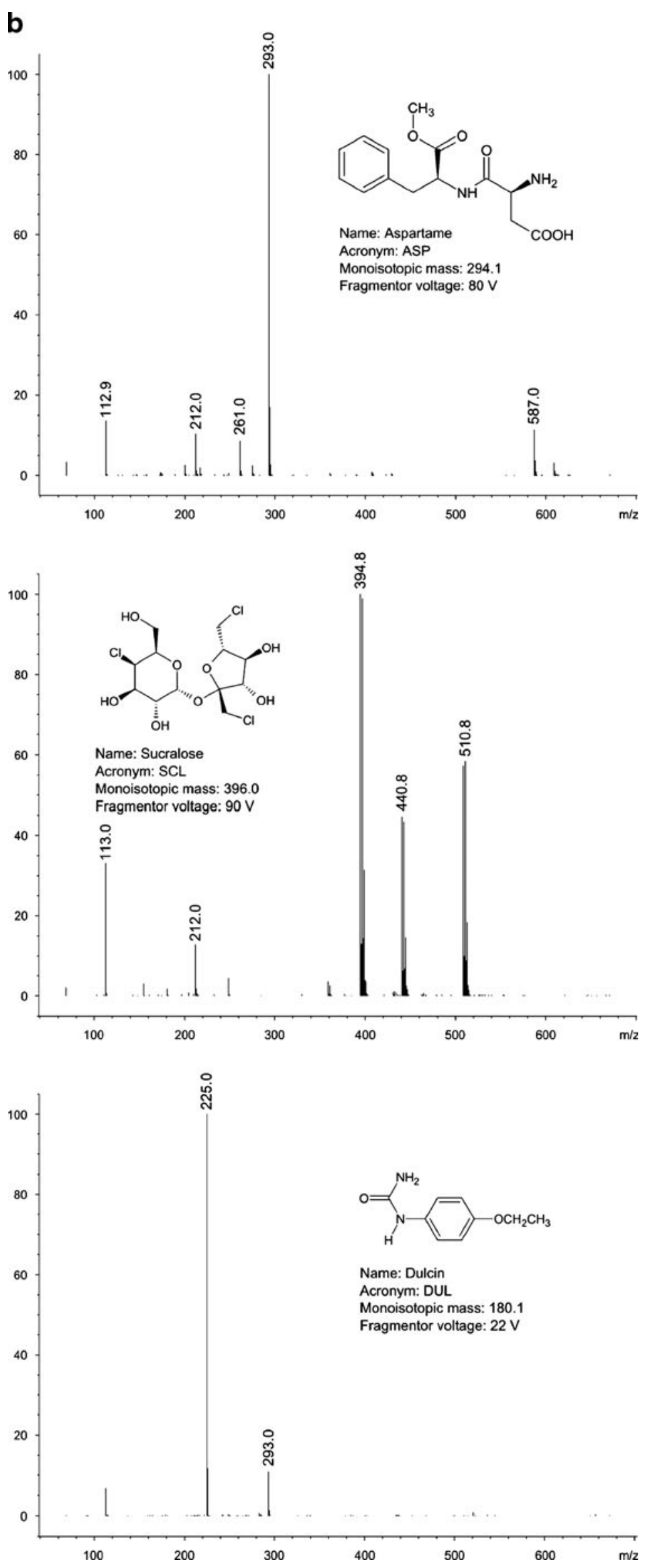
Fig. 1 (continued)
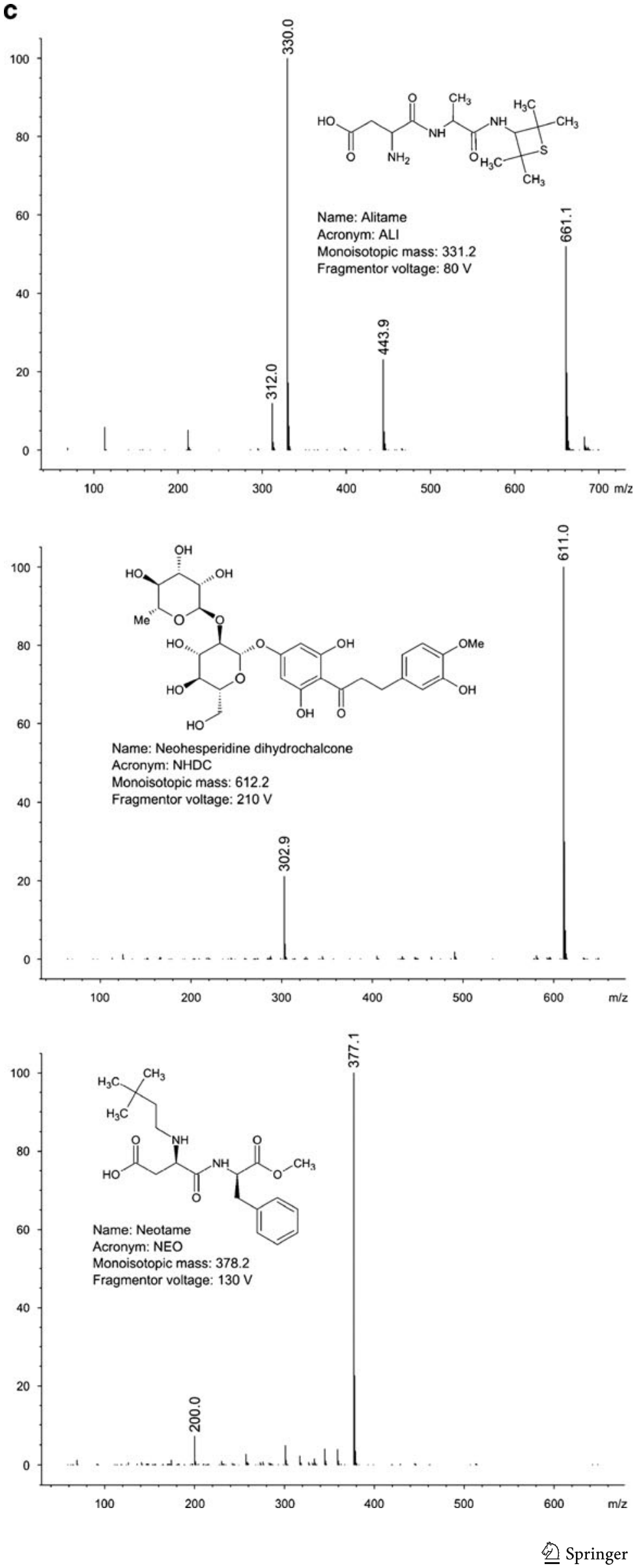
long retention times like alitame, neohesperidin dihydrochalcone or neotame. Since all "difficult" compounds giving non-linear responses from MSD (acesulfame, saccharin and sucralose) elute much earlier, we started to search for a compound that would fulfil three requirements. Firstly, it should elute between cyclamate and aspartame (Fig. 2a). Secondly, the compound should not be used in food industry, e.g. as a preservative, colourant or other additive. Thirdly, it must produce reasonable MS response. Several different substances (mostly pharmaceuticals) were tested, but none of them met our expectations; therefore, it was decided to synthesise such a compound. Under the separation conditions used, cyclamic acid elutes as a third compound with the retention time of c.a. $5.8 \mathrm{~min}$. Next, analyte (aspartame) elutes at c.a. 12.5 min leaving a 5-minwide time-window for an internal standard. Taking into account molecular structures of cyclamic acid and aspartame and their synthesis routes, it is obvious that the natural candidates for an internal standard were derivatives of cyclamic acid because their in-house synthesis is relatively
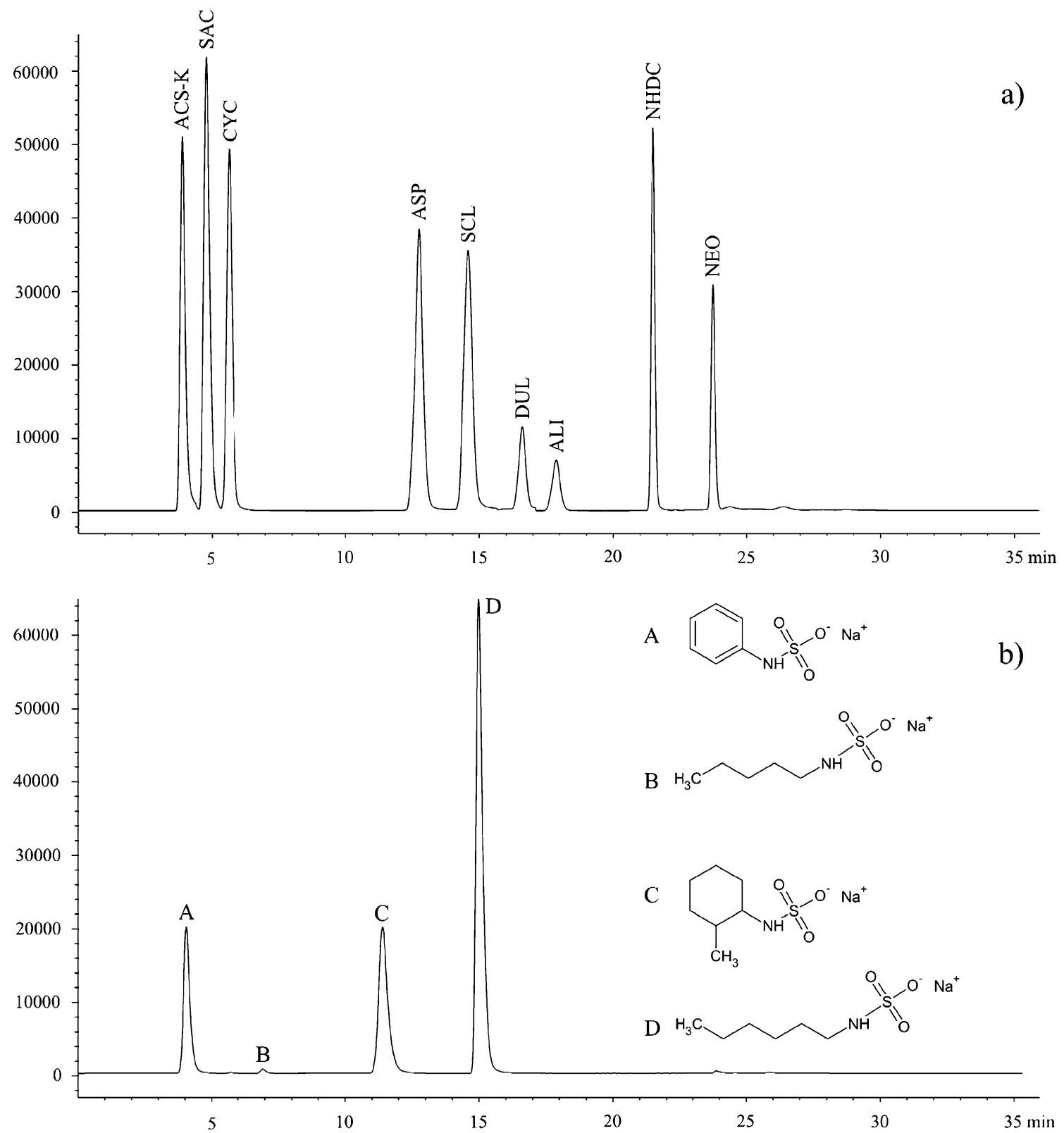

Fig. 2 Total ion chromatograms of $\mathbf{a}$ the mixture of analytes and $\mathbf{b}$ mixture of four candidates for an internal standard. Peak identification: $A C S-K$ acesulfame-K, $S A C$ saccharin, $C Y C$ cyclamate, $A S P$ aspartame, $S C L$ sucralose, DUL dulcin, $A L I$ alitame, NHDC neo-

hesperidin dihydrochalcone, $N E O$ neotame, $A N$-phenylsulfamate, $B$ $\mathrm{N}$-amylsulfamate, $\mathrm{C} \mathrm{N}$-(2-methylcyclohexyl)sulfamate, $D \mathrm{~N}$-hexylsulfamate 
cheap and easy [25]. Using different N-substituted amines, one can produce a variety of cyclamic acid derivatives without much effort.

Sodium salts of $N$-phenylsulfamic, $N$-amylsulfamic, $N$ hexylsulfamic and $N$-(2-methylcyclohexyl)sulfamic acids were synthesised by aminolysis of chlorosulfonic acid with a corresponding amine. Their structures and retention times (under the conditions used for separation of sweeteners under the study) are presented in Fig. 2b. Two out of four synthesised compounds fitted into the "gap" between cyclamate and aspartame; $N$-amylsulfamate and $N$-(2methylcyclohexyl)sulfamate. The latter was chosen as internal standard due to much better response of MS detector for this compound.

Ionisation suppression/enhancement

Possible matrix effect, i.e. ionisation suppression or enhancement were studied in order to decide what calibration approach (external or matrix-matched) should be applied. Selected samples of different foodstuffs (soft drink, vegetable salad and fish marinade), containing no sweeteners of interest, were subjected to SPE procedure. The final extracts were spiked with a mixture of analytes. In parallel, aliquots of mobile phase were spiked with the same amount of sweeteners' mixture, and both types of samples were analysed by HPLC/MS. No statistically significant differences (Student's $t$ test for differences between mean values at confidence level of $95 \%, n=5$ ) between those two series of injections were observed, therefore an external calibration approach has been applied.

\section{Extraction of sweeteners and clean-up procedure}

Many food products are very complex mixtures that contain variety of organic (lipids, carbohydrates, proteins, vitamins, dyes, preservatives, etc.) and inorganic (water, minerals, etc.) ingredients. Virtually all these substances can interfere with the final mass spectrometric detection of sweeteners causing signal suppression or enhancement. While proper chromatographic separation of sample components can solve this problem [23], long-term performance of an HPLC/MS system, constantly fed with raw sample extracts, will suffer. Extract clean-up is essential to keep an analytical system in top condition for as long as possible, which is especially important if the system is used for routine food analysis.

Suitability of different commercially available SPE sorbents and parameters affecting recovery of sweeteners from aqueous solutions have been studied and the details published elsewhere [26]. Composition and $\mathrm{pH}$ of the buffer used for extraction of analytes was found to be the most important factor affecting their recovery. Use of the buffer composed of formic acid and $N, N$-diisopropylethylamine ( $\mathrm{pH} 4.5$ ) yields very good recoveries (see Table 2) for all sweeteners and almost every reversed phase sorbent. In case of this work, Strata-X RP cartridges were chosen due to their advantageous performance/price ratio.

\section{Method performance}

\section{Linearity, limits of detection and limits of quantification of the method}

Seven-point calibration curves were constructed by plotting analyte to internal standard peak area ratios versus analyte concentration. Different concentration ranges for different sweeteners were chosen accordingly to their maximum usable doses defined by current legislation [3-7]. Calibration curves for ACS-K, SAC, CYC, ASP and SCL spanned from 0.1 to $40.0 \mu \mathrm{g} \mathrm{mL}^{-1}$ and from 0.1 to $8.0 \mu \mathrm{g} \mathrm{mL}^{-1}$ for ALI, DUL, NEO and NHDC. These correspond to $5 \div$ $2,000 \mu \mathrm{g} \mathrm{mL} L^{-1}(\mathrm{~g})$ and $5 \div 400 \mu \mathrm{g} \cdot \mathrm{mL}^{-1}(\mathrm{~g})$ in the original sample, respectively. Analysis of each calibration solution was performed in triplicate. Limits of detection (LODs) and limits of quantitation (LOQs) were determined by serial dilution of standard solutions. LODs and LOQs were

Table 1 Calibration data of nine high-intensity sweeteners

\begin{tabular}{|c|c|c|c|c|c|c|c|}
\hline Analyte & Curve equation & Concentration range $\left[\mu \mathrm{g} \cdot \mathrm{mL}^{-1}\right]$ & $S_{\mathrm{a}}$ & $S_{\mathrm{b}}$ & $R^{2}$ & LOD & LOQ \\
\hline ACS-K & $y=-0.0049 x^{2}+0.1874 x+0.0159$ & $0.1 \div 40.0$ & - & - & 0.9999 & 0.002 & 0.02 \\
\hline SAC & $y=-0.0019 x^{2}+0.1951 x+0.0153$ & $0.1 \div 40.0$ & - & - & 0.9997 & 0.001 & 0.03 \\
\hline CYC & $y=0.0184 x+0.001$ & $0.1 \div 40.0$ & 0.0017 & 0.030 & 0.9999 & 0.001 & 0.01 \\
\hline ASP & $y=0.1585 x-0.069$ & $0.1 \div 40.0$ & 0.0017 & 0.031 & 0.9994 & 0.01 & 0.05 \\
\hline SCL & $y=-0.0043 x^{2}+0.2344 x+0.1702$ & $0.1 \div 40.0$ & - & - & 0.9991 & 0.001 & 0.01 \\
\hline DUL & $y=0.3102 x+0.0046$ & $0.1 \div 8.0$ & 0.0011 & 0.0046 & 0.9999 & 0.002 & 0.01 \\
\hline ALI & $y=0.3097 x-0.0138$ & $0.1 \div 8.0$ & 0.0011 & 0.0045 & 0.9999 & 0.001 & 0.01 \\
\hline NHDC & $y=0.5899 x-0.035$ & $0.1 \div 8.0$ & 0.0029 & 0.013 & 0.9999 & 0.001 & 0.01 \\
\hline NEO & $y=0.4509 x-0.058$ & $0.1 \div 8.0$ & 0.0071 & 0.031 & 0.9993 & 0.005 & 0.02 \\
\hline
\end{tabular}

$S_{\mathrm{a}}$ standard deviation of the slope, $S_{\mathrm{b}}$ standard deviation of the intercept, $R^{2}$ coefficient of determination 
evaluated on the basis of a signal-to-noise ratio of 3 and 10 , respectively. Calibration data including calibration line equations, determination coefficients, limits of detection and quantitation are listed in Table 1.

Calibration curves were linear within the studied range of concentrations with coefficients of determination over 0.999 for six investigated sweeteners (CYC, ASP, ALI, DUL, NHDC, NEO). In case of ACS-K, SAC and SCL, calibration curves were non-linear, and they had to be approximated by second-degree polynomials.

\section{Trueness and repeatability study}

The trueness, repeatability and reproducibility of the method were tested with fortified samples of three representative food products: cola drink, yoghurt and home-made fish marinade. Before fortification, blank samples were analysed in order to check the presence of the analytes.

To determine trueness, each sample of a food product was divided into three sub-samples, and each sub-sample spiked at a different concentration level, 50\%, 100\% and $125 \%$ of MUD value. Every sub-sample was analysed in triplicate according to procedure described above. The results are presented in Table 2.

Satisfactory recoveries $(84.2 \div 106.7 \%)$, with relative standard deviations (RSDs) below 10\%, were obtained for all sweeteners regardless of the type of sample matrix and the spiking level.

The repeatability and reproducibility of the method was assessed by replicate analyses of three products (beverage, yoghurt and home-made fish marinade) at one spiking level ( $50 \%$ of MUD value). Three sub-samples of each product were analysed three times a day (nine sub-samples of each product a day) to determine the intra-day repeatability expressed as RSD of within-day averages. The analyses were repeated for three consecutive days to calculate interday reproducibility expressed as RSD of between-days averages. The results these studies are presented in Table 3 .

The intra-day repeatability was between $0.4 \div 4.7 \%, 0.6 \div$ $7.1 \%$ and $0.6 \div 8.9 \%$ for beverage, yoghurt and fish marinade samples, respectively. A more complicated matrix of yoghurt and fish marinade resulted in slightly higher variability of the results for theses samples.

The inter-day reproducibility was between $0.4 \div 6.3 \%$ and $0.7 \div 8.6 \%$ for beverage and yoghurt samples, respectively. In case of fish marinade, the inter-day reproducibility was between $0.5 \%$ and $9.6 \%$ for all but two compounds. Quick degradation of aspartame and neotame has been observed which resulted in much higher spread of the results of inter-day reproducibility for these two analytes (21.3\% and $32.4 \%$ for ASP and NEO, respectively).

The reasons for consecutive, day-by-day drop in recovery values observed for ASP and NEO in this matrix are not
Table 2 Recoveries (\%) and relative standard deviations RSD (\%) obtained by SPE-HPLC/MS analysis of three different food products fortified with a standard solutions of nine intense sweeteners at three spiking levels $(50 \%, 100 \%$ and $125 \%$ of maximum usable dose, MUD)

\begin{tabular}{|c|c|c|c|c|}
\hline \multirow[t]{2}{*}{ Analyte } & \multirow[t]{2}{*}{ MUD $^{\mathrm{a}}$} & \multicolumn{3}{|c|}{ Recovery (RSD) [\%] spiking level } \\
\hline & & $50 \%$ MUD & $100 \%$ MUD & $125 \%$ MUD \\
\hline \multicolumn{5}{|c|}{ Cola drink } \\
\hline ACS-K & 350 & $100.7(1.3)$ & $98.4(1.1)$ & $103.6(1.8)$ \\
\hline SAC & 80 & $95.3(1.3)$ & $89.9(2.7)$ & $92.9(1.4)$ \\
\hline $\mathrm{CYC}$ & 250 & $95.5(0.7)$ & $95.7(2.1)$ & $97.1(0.8)$ \\
\hline ASP & 600 & $88.5(0.6)$ & $88.7(2.2)$ & $92.3(0.7)$ \\
\hline SCL & 300 & $94.4(0.4)$ & $93.5(2.1)$ & $96.6(0.3)$ \\
\hline DUL & $20^{\mathrm{b}}$ & $99.8(0.4)$ & $105.7(1.8)$ & $106.2(3.4)$ \\
\hline ALI & $20^{\mathrm{b}}$ & $91.3(5.3)$ & $90.2(3.6)$ & $94.1(3.2)$ \\
\hline NHDC & 30 & $103.9(0.9)$ & $96.5(1.7)$ & $99.3(0.4)$ \\
\hline NEO & 20 & $95.3(1.0)$ & $92.7(1.4)$ & $96.2(0.4)$ \\
\hline \multicolumn{5}{|l|}{ Yoghurt } \\
\hline ACS-K & 350 & $96.4(1.5)$ & $97.5(1.3)$ & $98.8(0.4)$ \\
\hline SAC & 100 & $86.3(0.2)$ & $87.4(0.8)$ & $85.7(1.0)$ \\
\hline CYC & 250 & $101.7(2.5)$ & $98.3(3.9)$ & $96.3(0.6)$ \\
\hline ASP & 1000 & $86.2(1.2)$ & $88.4(2.9)$ & $99.7(1.8)$ \\
\hline SCL & 400 & $90.6(1.4)$ & $93.8(2.9)$ & $98.8(0.3)$ \\
\hline DUL & $20^{\mathrm{b}}$ & $99.5(6.1)$ & $102.5(3.2)$ & $100.2(1.4)$ \\
\hline ALI & $20^{\mathrm{b}}$ & $91.5(1.6)$ & $92.1(3.0)$ & $88.7(4.0)$ \\
\hline NHDC & 50 & $89.6(1.7)$ & $86.5(3.5)$ & $87.0(1.6)$ \\
\hline NEO & 32 & 90.7 (1.7) & $87.1(5.0)$ & 97.8 (1.9) \\
\hline \multicolumn{5}{|c|}{ Fish marinade } \\
\hline ACS-K & 200 & $96.5(3.4)$ & $101.1(2.4)$ & $104.7(0.7)$ \\
\hline SAC & 160 & $97.3(3.2)$ & $97.9(2.4)$ & $100.8(2.7)$ \\
\hline CYC & $200^{\mathrm{c}}$ & $98.3(4.4)$ & $88.4(3.8)$ & $101.7(2.0)$ \\
\hline ASP & 300 & $85.1(4.9)$ & $90.9(3.8)$ & $88.9(1.2)$ \\
\hline SCL & 120 & $91.4(7.5)$ & $100.2(4.5)$ & $106.7(0.3)$ \\
\hline DUL & $20^{\mathrm{b}}$ & $98.7(6.7)$ & $99.9(5.0)$ & $105.3(0.2)$ \\
\hline ALI & $20^{\mathrm{b}}$ & $96.3(9.2)$ & $99.3(4.4)$ & $103.9(0.7)$ \\
\hline NHDC & 30 & $89.3(8.7)$ & $85.0(4.4)$ & $88.2(2.2)$ \\
\hline NEO & 20 & $87.8(9.8)$ & $84.2(4.3)$ & $88.4(0.5)$ \\
\hline
\end{tabular}

${ }^{\mathrm{a}}$ Beverages, in milligrammes per litre, yoghurt and fish marinade, in milligrammes per kilogramme

${ }^{\mathrm{b}}$ Not allowed for use in foodstuffs according to the EU directives; proposed value

${ }^{c}$ Not authorised for use in fish products according to the EU directives, proposed value

clear. At first, relatively low stability of aspartame in acidic environment was blamed. And since the structures of aspartame and neotame are very similar, that could explain degradation of neotame too. However, after checking the $\mathrm{pH}$ of fish marinade homogenisate $(\mathrm{pH}=4.3)$, we had to exclude the chemical degradation/hydrolysis hypothesis since aspartame is most stable around this $\mathrm{pH}$ value and 
Table 3 Intra-day repeatability and inter-day reproducibility of assay, samples (MUD=50\%) analysed three times a day on three consecutive days

\begin{tabular}{|c|c|c|c|c|}
\hline \multirow[t]{3}{*}{ Analyte } & \multicolumn{3}{|c|}{ Recovery (RSD [\%]) } & \multirow[t]{3}{*}{ Inter-day $(n=3)$} \\
\hline & \multicolumn{3}{|c|}{ Intra-day $(n=3)$} & \\
\hline & Day 1 & Day 2 & Day 3 & \\
\hline \multicolumn{5}{|c|}{ Cola drink } \\
\hline ACS-K & $104.2(1.1)$ & $98.6(2.1)$ & 95. $6(3.9)$ & $99.1(4.6)$ \\
\hline SAC & $96.4(0.5)$ & $93.6(0.7)$ & $94.6(1.7)$ & $95.1(1.2)$ \\
\hline CYC & $106.0(1.2)$ & $107.5(0.7)$ & $106.7(1.0)$ & $106.5(0.4)$ \\
\hline ASP & $86.9(2.1)$ & $84.7(1.8)$ & $83.9(3.7)$ & $84.8(2.1)$ \\
\hline SCL & $99.7(0.8)$ & $96.4(1.5)$ & $105.0(2.7)$ & $100.1(4.7)$ \\
\hline DUL & $101.5(2.7)$ & $104.6(1.0)$ & $104.2(2.3)$ & $103.8(2.0)$ \\
\hline ALI & $85.8(1.7)$ & $85.7(4.7)$ & $88.4(4.6)$ & 87.7 (1.9) \\
\hline NHDC & $101.6(0.9)$ & $98.8(1.4)$ & $91.6(3.7)$ & $97.4(5.3)$ \\
\hline NEO & $87.6(0.2)$ & $85.8(1.4)$ & $82.5(3.5)$ & $85.3(2.6)$ \\
\hline \multicolumn{5}{|l|}{ Yoghurt } \\
\hline ACS-K & $103.3(1.1)$ & $97.0(0.9)$ & $87.0(3.4)$ & $95.7(8.6)$ \\
\hline SAC & $92.2(1.3)$ & $87.8(1.8)$ & $88.3(3.7)$ & $89.4(2.7)$ \\
\hline $\mathrm{CYC}$ & $106.7(0.7)$ & $105.3(1.5)$ & $107.9(1.5)$ & $106.6(1.3)$ \\
\hline ASP & $86.6(3.2)$ & $86.2(2.7)$ & $87.4(2.0)$ & $86.7(0.7)$ \\
\hline $\mathrm{SCL}$ & $99.6(5.5)$ & $98.2(3.9)$ & $105.1(0.6)$ & $101.0(3.6)$ \\
\hline DUL & $103.8(2.1)$ & $101.4(1.7)$ & $104.6(1.8)$ & $103.3(1.6)$ \\
\hline ALI & $97.5(7.1)$ & $100.4(4.4)$ & $105.5(5.5)$ & $101.1(4.0)$ \\
\hline NHDC & $89.3(5.5)$ & $88.2(0.9)$ & $82.9(2.8)$ & $86.8(3.9)$ \\
\hline NEO & $100.0(3.3)$ & $97.0(3.8)$ & $92.8(3.2)$ & $96.6(3.7)$ \\
\hline \multicolumn{5}{|c|}{ Fish marinade } \\
\hline ACS-K & $104.2(1.0)$ & $102.7(0.9)$ & $90.4(0.9)$ & 99.1 (7.6) \\
\hline SAC & $95.2(2.5)$ & $91.9(3.5)$ & $83.6(1.5)$ & $90.2(6.6)$ \\
\hline CYC & $104.4(3.3)$ & $104.2(4.7)$ & $99.3(1.2)$ & $102.6(2.8)$ \\
\hline ASP & $90.0(4.8)$ & $69.2(3.3)$ & $59.6(3.0)$ & $73.0(21.3)$ \\
\hline SCL & $102.6(4.8)$ & $100.5(3.7)$ & $99.8(2.8)$ & $101.0(1.4)$ \\
\hline DUL & $100.7(6.3)$ & $89.2(5.8)$ & $88.5(3.0)$ & $92.8(7.4)$ \\
\hline ALI & $103.0(2.4)$ & $103.4(0.2)$ & $104.1(1.6)$ & $103.5(0.5)$ \\
\hline NHDC & $84.5(6.4)$ & $76.4(2.4)$ & $69.8(3.4)$ & $56.9(9.6)$ \\
\hline NEO & $90.3(8.9)$ & $61.7(5.0)$ & $48.0(7.0)$ & $66.6(32.4)$ \\
\hline
\end{tabular}

the recovery rate drop was too fast. Another factor that could be responsible for low recoveries of ASP and NEO was bacterial activity. Home-made fish marinade was not sterilised or pasteurised. No preservatives were added to the product, except for some spices and onion. But again, speed of the recovery drop and the fact that samples were stored at $+4{ }^{\circ} \mathrm{C}$ between analyses made this theory sound unrealistic. Normally, fish marinades do not show symptoms of rotting/degradation for at least 2 weeks when stored properly in a fridge.

Finally, we come to the conclusion that the losses of ASP and NEO were most probably caused by decomposition of these two dipeptide sweeteners by proteolytic enzymes released from fish cells during sample homogenisation. Further investigations are necessary, however, to verify this hypothesis.
Whatever is the cause of this phenomenon, it does not affect applicability of the proposed method to analyse such kind of foodstuffs simply because neither aspartame nor neotame are used during production of fish marinades.

\section{Analyses of real-world samples}

Over 30 various real-world food samples were analysed using the method described here. All products were bought at local stores. Most of the samples contained sweeteners (as declared by manufacturer), but several samples declared as sweetener-free were analysed too. Every sample was analysed in triplicate. Correctness of the labelling and conformance to the EU legislation [3] were verified. Results of this survey are shown in Table 4. Examples of chromatograms are given in Fig. 3. 
Table 4 Results of a survey concerning number and amount of high-intensity sweeteners present in the samples purchased in local stores in Gdańsk

\begin{tabular}{|c|c|c|c|c|c|c|}
\hline \multirow[t]{2}{*}{ Sample type } & \multirow[t]{2}{*}{ Sample no. } & \multicolumn{5}{|c|}{ Sweetener content $\left[\mathrm{mg} \cdot \mathrm{L}^{-1}\right.$ or $\left.\mathrm{mg} \cdot \mathrm{kg}^{-1} \pm \mathrm{SD}(n=3)\right]$} \\
\hline & & ACS-K & SAC & $\mathrm{CYC}$ & ASP & SCL \\
\hline \multirow[t]{7}{*}{ Carbonated drinks } & 1 & $128.5 \pm 1.2$ & & & $443.3 \pm 7.1$ & \\
\hline & 2 & $72.8 \pm 1.5$ & & $237.7 \pm 3.1$ & $149.1 \pm 1.9$ & \\
\hline & 3 & $17.8 \pm 0.3$ & $11.6 \pm 0.9$ & $95.8 \pm 1.5$ & $11.3 \pm 0.5$ & \\
\hline & 4 & & & & $220.2 \pm 1.8$ & \\
\hline & 5 & $215.2 \pm 1.5$ & $173.7 \pm 4.0$ & $48.7 \pm 0.2$ & & \\
\hline & 6 & $110.4 \pm 1.2$ & & & $215.4 \pm 1.3$ & \\
\hline & 7 & $98.1 \pm 0.5$ & & & $290.8 \pm 0.9$ & \\
\hline \multirow[t]{4}{*}{ Non-carbonated drinks } & 8 & & & & & $105.8 \pm 0.7$ \\
\hline & 9 & $25.2 \pm 0.1$ & & & & $53.1 \pm 1.0$ \\
\hline & 10 & $65.5 \pm 0.5$ & & & $47.5 \pm 1.2$ & \\
\hline & 11 & $23.1 \pm 0.4$ & & $111.6 \pm 1.9$ & $105.4 \pm 1.2$ & \\
\hline \multirow[t]{3}{*}{ Juices } & 12 & $22.9 \pm 0.1$ & & $181.9 \pm 2.9$ & & $91.3 \pm 1.5$ \\
\hline & 13 & & $20.7 \pm 0.5$ & $53.3 \pm 2.7$ & & \\
\hline & 14 & $33.7 \pm 0.2$ & $44.1 \pm 0.5$ & $211.7 \pm 3.6$ & $70.0 \pm 1.8$ & \\
\hline \multirow[t]{2}{*}{ Beers } & 15 & & $17.9 \pm 0.5$ & $123.7 \pm 5.1$ & & \\
\hline & 16 & $28.9 \pm 1.8$ & $11.8 \pm 0.3$ & & $64.7 \pm 0.5$ & \\
\hline \multirow[t]{6}{*}{ Yoghurts } & 17 & & & & & $266.3 \pm 2.4$ \\
\hline & 18 & $142.6 \pm 1.4$ & & & $117.5 \pm 1.1$ & \\
\hline & 19 & None detect & greement wi & ufacturer's de & & \\
\hline & 20 & $125.8 \pm 2.3$ & & & $244.5 \pm 3.4$ & \\
\hline & 21 & & & & & $149.7 \pm 3.1$ \\
\hline & 22 & None detect & greement wi & ufacturer's de & & \\
\hline \multirow[t]{6}{*}{ Fish marinades } & 23 & & $119.2 \pm 2.3$ & & & \\
\hline & 24 & & $95.7 \pm 0.6$ & & & \\
\hline & 25 & $27.3 \pm 0.2^{\mathrm{a}}$ & $45.3 \pm 0.2^{\mathrm{a}}$ & $132.5 \pm 0.1^{\mathrm{a},}$ & & \\
\hline & 26 & & $63.4 \pm 1.5$ & & & \\
\hline & 27 & None detect & greement wi & ufacturer's de & & \\
\hline & 28 & & $47.6 \pm 2.3^{\mathrm{a}}$ & $85.9 \pm 4.2^{\mathrm{a},}$ & & \\
\hline \multirow[t]{4}{*}{ Fish salads } & 29 & & $73.7 \pm 2.1$ & & & \\
\hline & 30 & & $40.8 \pm 0.6$ & & & \\
\hline & 31 & None detect & greement wi & ufacturer's de & & \\
\hline & 32 & $25.4 \pm 0.5$ & $62.8 \pm 0.4$ & & & \\
\hline \multirow[t]{4}{*}{ Fish pastes } & 33 & None detect & greement wi & ufacturer's de & & \\
\hline & 34 & & $80.5 \pm 0.2$ & & & \\
\hline & 35 & & $40.0 \pm 0.6$ & & & \\
\hline & 36 & & $55.9 \pm 1.0$ & & & \\
\hline
\end{tabular}

${ }^{\text {a }}$ Compound not listed in the label

${ }^{\mathrm{b}}$ According to EU directives, CYC is not allowed for use in fish preserves

Five authorised high-intensity sweeteners were found in the samples: ACS-K, SAC, CYC, ASP and SCL. Saccharin and acesulfame were found to be the most commonly used sweeteners. They were found in majority of 31 sweetener containing products (SAC, 17 samples; ACS-K, 16 samples). Slightly less popular are aspartame and cyclamate (ASP, 11 samples; CYC, ten samples). Sucralose was found in five samples. No other high-intensity sweeteners were detected.
Beverages were the most interesting group of foods in terms of sweeteners' composition. Almost half of the tested drinks contained three or four component sweetener blends. Two-component mixtures were also popular while a single sweetener was used in only two cases out

Fig. 3 Total ion chromatograms (normalised against IS) of selected real-world samples. A yoghurt (a), a drink (b) and a fish marinade (c) 
Determination of nine high-intensity sweeteners by HPLC-MS

2171
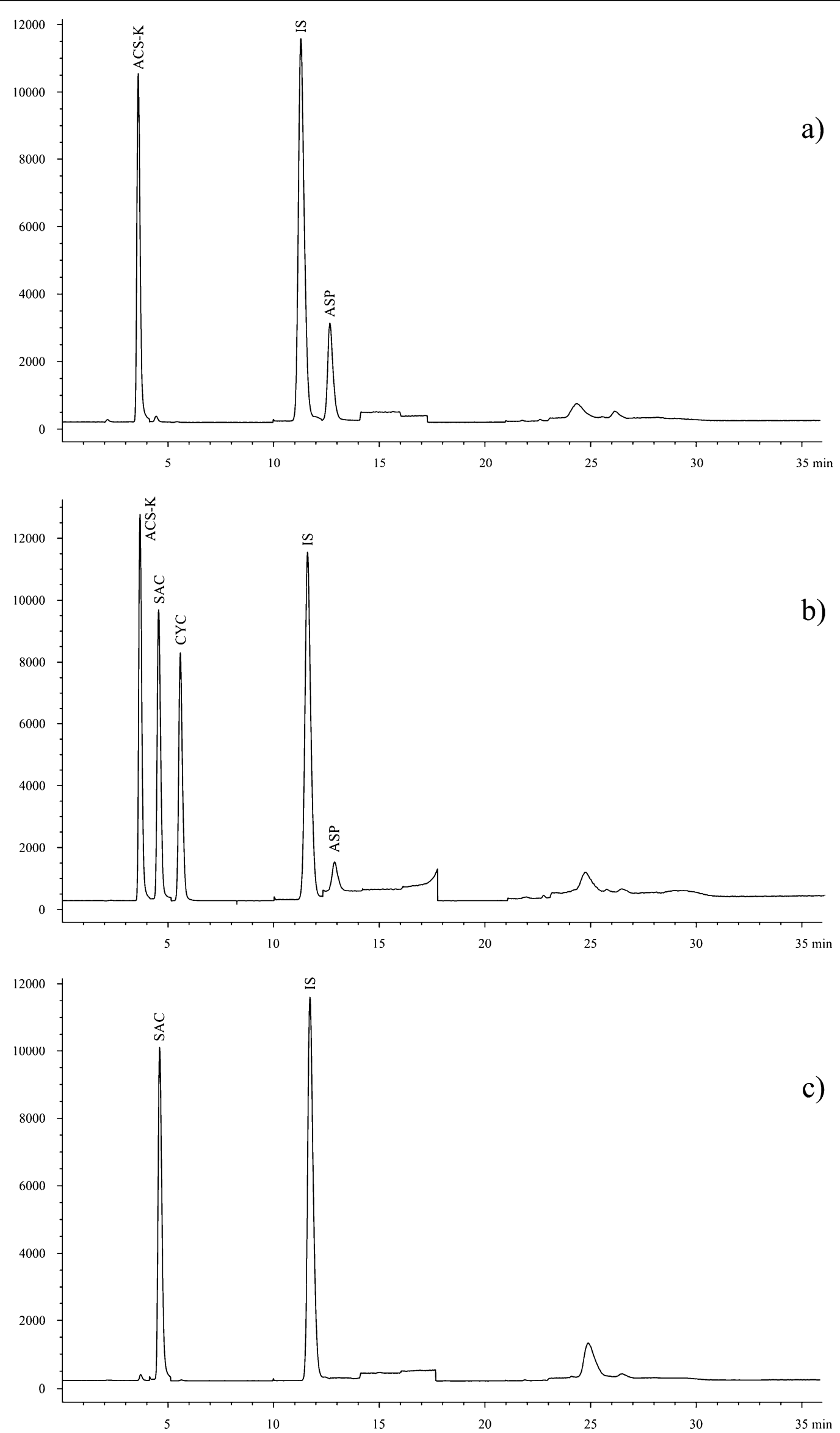

Springer 
of 16 analysed. Other foods (i.e. yoghurts and fish-based products) were sweetened with just one or a mixture of two sweeteners.

In general, all products were properly labelled, and the sweeteners' content was within legal limits. There were two cases of fish marinades containing - not authorised for this kind of foods - cyclamate. Additionally, one of them also contained acesulfame and saccharin, none of which were listed among ingredients.

\section{Conclusions}

An HPLC/MS method for simultaneous determination of all but one high-intensity sweetener authorised in EU (the only exception is thaumatine) and two unauthorised has been described. Application of mass spectrometry allowed for highly sensitive and selective determination of all studied compounds in one chromatographic run. Sample extract clean-up step using solid-phase extraction has been improved by introduction of $N, N$-diisopropylethylamine as a component of an extraction buffer. A derivative of cyclamate, $N$-(2-methylcyclohexyl)sulfamic acid has been proposed as a new internal standard for mass spectrometric determination of high-intensity sweeteners. It seems that a combination of this early eluting compound with lateeluting warfarin should give a perfect combination of internal standards that effectively compensate for instability of an MS detector's response.

The proposed method has been successfully applied for determination of high-intensity sweeteners in three different types of the real-world samples: beverages, yoghurts and fish products.

Acknowledgements This work was financially supported by the Polish Committee for the Scientific Research (research projects $\mathrm{N}$ N404 027535 and N N312 239139) and Foundation for Polish Science (MISTRZ programme 2009 edition).

Open Access This article is distributed under the terms of the Creative Commons Attribution Noncommercial License which permits any noncommercial use, distribution, and reproduction in any medium, provided the original author(s) and source are credited.

\section{References}

1. Mitchell H (2006) Sweeteners and sugar alternatives in food technology. Blackwell, Oxford

2. Nollet LML (2000) Food analysis by HPLC. Marcel Dekker, New York

3. (1994) Directive 94/35/EC of European Parliament and of the Council of 30 June 1994 on sweeteners for use in foodstuffs. Official Journal of European Communities, L237/13

4. (1997) Directive 96/83/EC of European Parliament and of the Council of 19 December 1996 on sweeteners for use in foodstuffs. Official Journal of European Union, L048/16

5. (2003) Directive 2003/115/EC of European Parliament and of the Council of 22 December 2003 amending Directive 94/35/EC on sweeteners for use in foodstuffs

6. (2006) Directive 2006/52/EC of European Parliament and of the Council of 5 July 2006 amending Directive 95/2/EC on food additives other than colours and sweeteners and Directive 94/35/EC

7. (2009) Commission Directive 2009/163/EU of 22 December 2009 amending Directive 94/35/EC of the European Parliament and of the Council on sweeteners for use in foodstuffs with regard to neotame

8. Zygler A, Wasik A, Namieśnik J (2009) Trac 28:1082-1102

9. Cubuk Demiralay E, Ozkan G, Guzel-Seydim Z (2006) Chromatographia 63:91-96

10. Dossi N, Toniolo R, Susmel S, Pizzarello A, Bontempelli G (2006) Chromatographia 63:557-562

11. Chen Q, Mou SF, Liu K, Yang Z, Ni Z (1997) J Chromatogr A 771:135-143

12. Zhu Y, Guo Y, Ye M, James FS (2005) J Chromatogr A 1085:143-146

13. Spangenberg B, Stroka J, Arranz I, Anklam E (2003) J Liq Chromatogr Related Technol 26:2729-2739

14. Galletti GC, Chiavari G, Bocchini P (1995) J Anal Appl Pyrolysis 32:137-151

15. Herrmannova M, Krivankova L, Bartos M, Vytras K (2006) J Sep Sci 29:1132-1137

16. Garcia-Jimenez JF, Valencia MC, Capitan-Valvey LF (2006) Anal Lett 39:1333-1347

17. Medeiros RA, de Carvahlo AE, Rocha-Filho RC (2008) Talanta 76:685-689

18. Ni Y, Xiao W, Kokot S (2009) Food Chem 113:1339-1345

19. Llamas NE, Di Nezio MS, Palomeque ME, Fernandez-Band BS (2008) Food Anal Methods 1:43-48

20. Armenta S, Garrigues S, de la Guardia M (2004) J Agric Food Chem 52:7798-7803

21. Wasik A, McCourt J, Buchgraber M (2007) J Chromatogr A 1157:187-196

22. Koyama M, Yoshida K, Uchibori N, Wada I, Akiyama K, Sasaki T (2005) Shokuhin Eiseigaku Zasshi 46:72-78

23. Yang D, Chen B (2009) J Agric Food Chem 57:3022-3027

24. (1963) Organic Syntheses Coll. 4:52; (1951) 31:11 http://www. orgsyn.org/orgsyn/pdfs/CV4P0052.pdf (accessed May 2010)

25. Audrieth LF, Sveda M (1944) J Org Chem 9:89

26. Zygler A, Wasik A, Namieśnik J (2010) Talanta 82:1749-1756 